\title{
THE DIII-D \\ CRYOGENIC SYSTEM UPGRADE
}

by

K.M. SCHAUBEL, G.J. LAUGHON, G.L. CAMPBELL, A.R. LANGHORN, N.C. STEVENS, and M.L. TUPPER

This is a preprint of a paper to be presented at the 15th IEEE Symposium on Fusion Engineering, October 11-15, 1993, Cape Cod, Massachusetts, and to be printed in the Proceedings.

\author{
Work supported by \\ U.S. Department of Energy \\ Contract DE-AC03-89ER51114
}

\section{GENERAL ATOMICS PROJECT 3466 OCTOBER 1993}

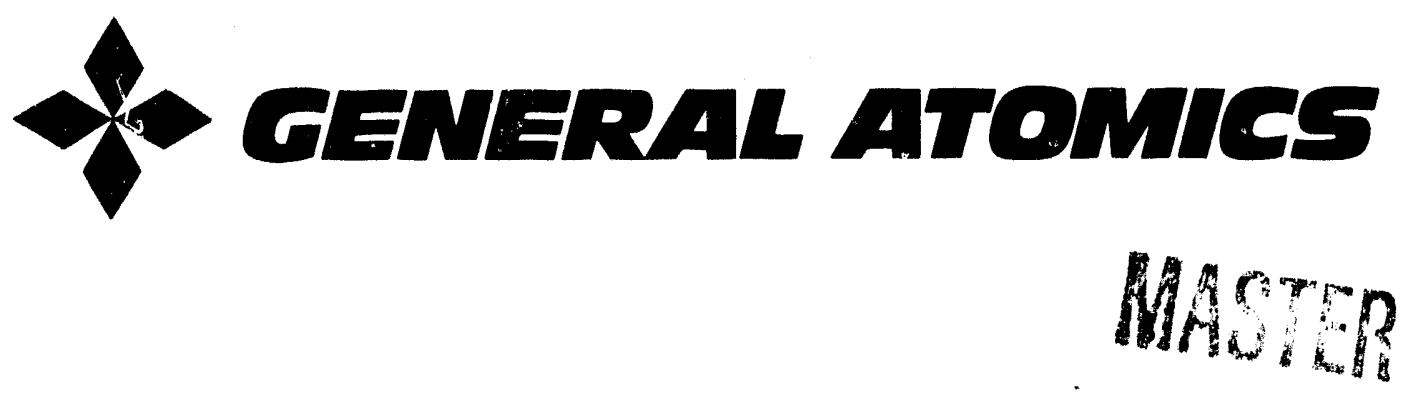




\title{
THE DIII-D CRYOGENIC SYSTEM UPGRADE
}

\author{
K.M. Schaubel, G.J. Laughon, G.L. Campbell, A.R. Langhorn, N.C. Stevens, and M.L. Tupper \\ General Atomics \\ P.0. Box 85608, San Diego, California 92186-9784
}

\begin{abstract}
The original DIII-D cryogenic system was commissioned in 1981 and was used to cool the cryopanel arrays for three hydrogen neutral beam injectors. Since then, new demands for liquid helium have arisen including: a fourth neutral beam injector, ten superconducting magnets for the electron cyclotron heating gyrotrons, and more recently, the advanced divertor cryopump which resides inside the tokamak vacuum vessel. The original cryosystem could not meet these demands. Consequently, the cryosystem was upgraded in several phases to increase capacity, improve reliability, and reduce maintenance. The majority of the original system has been replaced with superior equipment. The capacity now exists to support present as well as future demands for liquid helium at DIII-D including a hydrogen pellet injector, which is being constructed by Oak Ridge National Laboratory. Upgrades to the cryosystem include: a recently commissioned $150 \mathrm{l} / \mathrm{hr}$ helium liquefier, two $55 \mathrm{~g} / \mathrm{sec}$ helium screw compressors, a fully automated 20-valve cryogen distribution box, a high efficiency helium wet expander, and the conversion of equipment from manual or pneumatic to programmable logic controller (PLC) control. The distribution box was designed and constructed for compactness due to limited space availability. Overall system efficiency was significantly improved by replacing the existing neutral beam reliquefier Joule-Thomson valve with a reciprocating wet expander. The implementation of a PLC-based automatic control system has resulted in increased efficiency and reliability. This paper will describe the cryosystem design with emphesis on newly added equipment. In addition, performance and operational experience will be discussed.
\end{abstract}

\section{INTRODUCTION}

The DIII-D cryosystem was commissioned in 1981 to supply liquid nitrogen (LN2) and liquid helium (LHe) to three neutral beam injector cryopanel arrays [1]. This system had an LHe production rate of $80 \mathrm{l} / \mathrm{hr}$ and employed a Koch Process model 2800R liquefier with reciprocating expanders and five Koch Process model RS compressors. A single reliquefier consisting of a large heat exchanger and a Joule-Thomson valve was used to recover refrigeration from the two phase helium returning from the beamlines. Control of the system was largely manual and maintenance requirements were relatively high due to the liquefier's reciprocating expanders and the five compressors which required maintenance every $2000 \mathrm{hr}$.
Upgrades to the cryosystem have been performed as demands for liquid helium at DIII-D have increased (Table I). The common goal of these upgrades was to provide additional capacity, to increase the system reliability, and reduce maintenance requirements. In addition, upgrades of the control system have increased the system automation.

\section{PRESENT CRYOSYSTEM CONFIGURATION}

The present DIII-D cryosystem supplies LHe and LN2 to four neutral beam injector cryopanels [2], ten electron cyclotron heating (ECH) superconducting magnets, the advanced divertor cryopump, and the GRECE diagnostic instrument. The recently commissioned advanced divertor cryopump resides inside the tokamak plasma containment vessel where it provides particle exhaust pumping [3]. A deuterium pellet injector system supplied by Oak Ridge National Laboratory will be installed and commissioned in 1994. Table II lists the cryogenic users and their respective heat loads on the cryosystem.

A flow diagram of the cryosystem is shown in Fig. 1. Two helium compressors operating at 16 bar supply up to $110 \mathrm{~g} / \mathrm{sec}$ of room-temperature gas to the liquefier and the reliquefiers. The helium liquefier cools the high pressure gas using LN2 precooling followed by a series of expansions before finally discharging LHe into the $3800 \ell$ dewar. The liquefier is equipped with a control valve

Table I

DIII-D Cryosyitem Upgrade History

\begin{tabular}{|c|c|}
\hline Year & Event \\
\hline 1981 & $\begin{array}{l}\text { Doublet III cryonystem commiscioned to support } \\
\text { throe beamlines }\end{array}$ \\
\hline 1986 & ECH superconducting magnets operational \\
\hline 1988 & DIII-D upgrade, fourth beamline added \\
\hline 1987 & $\begin{array}{l}\text { Wet expander added to improve four beamline } \\
\text { reliquefaction efficiency }\end{array}$ \\
\hline 1988 & $\begin{array}{l}\text { Large Sullair compreavor added to replece maller } \\
\text { aging compreasorw; new cooling tower added }\end{array}$ \\
\hline 1992 & $\begin{array}{l}\text { Second Sullair compreasor added to increase } \\
\text { system capecity }\end{array}$ \\
\hline 1892 & $\begin{array}{l}\text { Manual distribution box replaced with 20-valve } \\
\text { mutomated distribution box }\end{array}$ \\
\hline 1893 & $\begin{array}{l}\text { New liquefier commimaioned to increase overall } \\
\text { capacity in preparation for the edvanced divertor } \\
\text { cryopump and pellet injector }\end{array}$ \\
\hline $\begin{array}{l}1993 \\
1994\end{array}$ & $\begin{array}{l}\text { Advanced divertor cryopump commincioned } \\
\text { Commisaioning of deuterium pellet injector planned }\end{array}$ \\
\hline
\end{tabular}

Manuecript received October 12, 1893. This is a report of work sponsored by the U.S. Depertment of Energy under Contrect No. DE-AC03-89ER51114. 
Table II

DIII-D Cryouystem Heat Loads and Cryogen Conoumption

\begin{tabular}{lll}
\multicolumn{1}{c}{ Device } & \multicolumn{1}{c}{ LHe } & \multicolumn{1}{c}{ LN2 } \\
\hline Neutral beam injectors (4) & $40 \ell / \mathrm{hr}+60 \mathrm{~W}$ at $4.6 \mathrm{~K}$ & $320 \mathrm{l} / \mathrm{hr}$ \\
Advanced divertor pump & $25 \mathrm{hr}+17 \mathrm{~W}$ at $4.6 \mathrm{~K}$ & $80 \ell / \mathrm{hr}$ \\
Pellet injector & $20 \ell / \mathrm{hr}$ & none \\
ECH megnets (10) & $10 \ell / \mathrm{hr}$ & $\approx 3 \ell / \mathrm{hr}$ \\
GRECE diagnostic & $0.2 \ell / \mathrm{hr}$ & $0.6 \ell / \mathrm{hr}$ \\
Storage dewar & $0.0 \ell / \mathrm{hr}+0.5 \mathrm{~W}$ at $4.6 \mathrm{~K}$ & 0 \\
Liquefier precool & 0 & $110 \ell / \mathrm{hr}$ \\
\hline Totals & $95 \ell / \mathrm{hr}+78 \mathrm{~W}$ at $4.6 \mathrm{~K}$ & $514 \ell / \mathrm{hr}$ \\
\hline
\end{tabular}

which maintains the dewar at 1.43 bar, allowing $4.6 \mathrm{~K}$ gas to vent to the compressor suction line while providing refrigeration as it passes through the low pressure side of the liquefier heat exchangers. The pressurized LHe in the dewar is force flowed to the distribution box at $4.6 \mathrm{~K}$. LHe is then supplied to the neutral beam injectors, advanced divertor cryopump, and pellet injector via the control valves on the distribution box. The helium gas storage tanks vary in pressure acting as a buffer to store excess gas or provide the system with make-up helium as needed.

Liquid nitrogen is supplied from a $40,000 \ell$ bulk storage tank which is telemonitored and filled by an outside supplier. LN2 is used to cool radiation shielding in the neutral beam injectors, advanced divertor cryopump, ECH magnets, and for various diagnostics. The liquefier uses liqu:d nitrogen to precool the incoming gaseous helium to $77 \mathrm{~K}$. All nitrogen boil-off is vented to the atmosphere.

LHe is fed to each of the four beamlines at a flowrate of $140 \mathrm{l} / \mathrm{hr}$ to ensure two-phase flow stability in the cryopanels. The returning two-phase helium is piped to the primary side of the reliquefier heat exchanger where it is warmed to $290 \mathrm{~K}$ and then fed into the compressor suction line. A side stream of high pressure gas is taken from the compressor discharge and counterflowed in the secondary side of the reliquefier heat exchanger. The counterflow stream exits the heat exchanger as a gas at 12 bar and $7 \mathrm{~K}$ before passing through the wet expander. It leaves the wet expander and enters the LHe dewar as a two-phase mixture at $1.43 \mathrm{bar}$. The liquid phase is separated and remains in the dewar while the cold gas phase provides refrigeration as it passes through the low pressure side of the liquefier heat exchangers via the pressure controlled return valve. The advanced divertor cryopump helium flow circuit operates in a similar manner except that it utilizes a separate heat exchanger/ Joule-Thomson valve reliquefier. Liquid helium is force flowed to the advanced divertor cryopump at a rate of $155 \ell / \mathrm{hr}$.

Liquid helium from the main dewar is transferred into intermediate dewars for distribution to the ECH magnets and the GRECE diagnostic. Room temperature helium boiloff from the magnets is piped to the compressor suction line for recovery. The pellet injector will utilize a dedicated $500 \ell$ dewar which will be batch-filled daily via a $60 \mathrm{~m}$ transferline connected to the distribution box. Helium boiloff from the pellet injector will also be recovered at room temperature.

All of the cryogenic users are located in areas which are inaccessible during plasma operations. Therefore, remote control of these systems is mandatory. The cryo genics production equipment is located outside of the DIII-D shield wall and is accessible during plasma operations. Fig. 2 shows the equipment arrangenient.

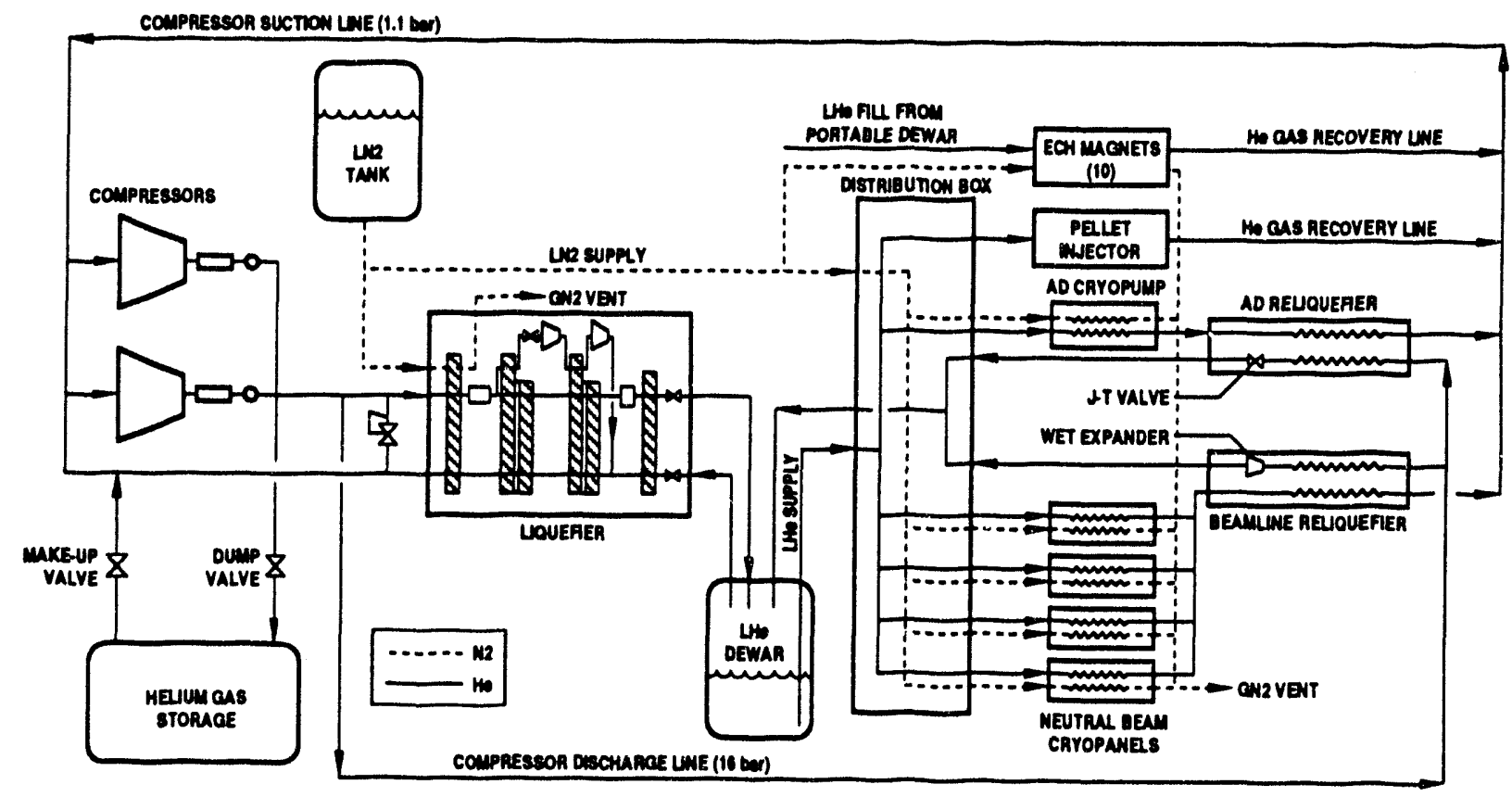

FIG. 1. DIII-D cryosystem flow diagram (simplified). Dashed lines indicate LN2, solid lines LHe. 


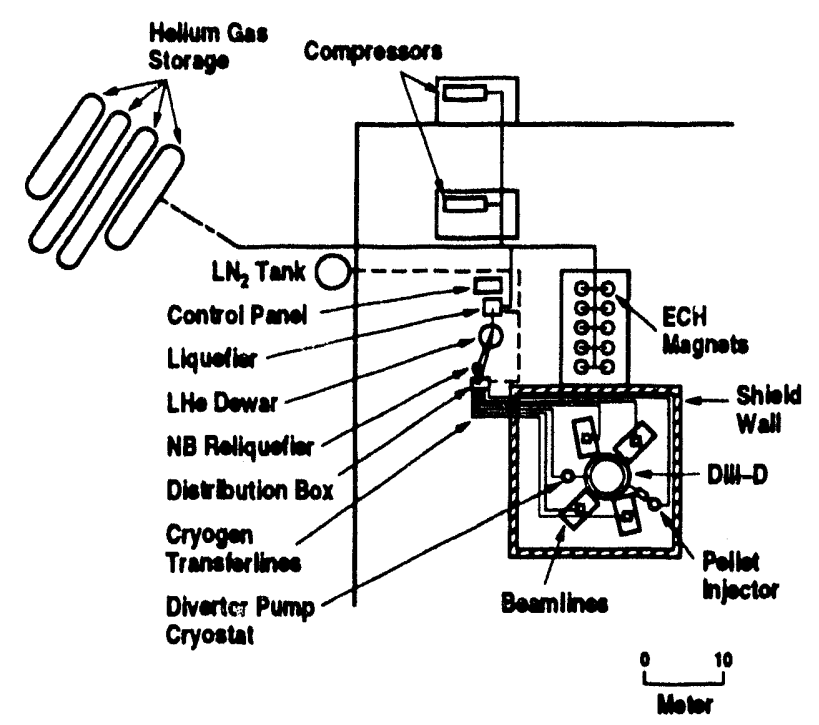

Fig. 2. Plan view showing the DIII-D cryosystem equipment arrangement.

\section{SYSTEM UPGRADES}

The cryosystem, as originally commissioned to support the operation of three neutral beam injectors, had limited excess capacity. Incremental improvements making use of available equipment and a restrictive cryosystem budget provided sufficient capacity when the fourth beamline and ten ECH magnets were added. However, the recent introduction of the advanced divertor cryopump and the planned addition of a pellet injector forced a major upgrade of the system. This major upgrade included a new $150 \mathrm{l} / \mathrm{hr}$ liquefier, two large rotary screw compressors, an automated cryogen distribution box, increased gas storage capacity, and major additions and improvements in the PLC based control system. The main parameters of the upgraded cryosystem are shown in Table III. A detailed description of the control system can be found in $[4,5]$.

\section{A. Liquefier}

The Sulzer model TCF 50 helium liquefier was commissioned in January 1993. The liquefier uses LN2 precooling, aluminum plate-fin heat exchangers, two dynamic gas bearing turbine expanders, and a PLC based control system which operates the liquefier automatically during croldown, steady-state operation, and warmup. With a measured liquefaction rate of $170 \mathrm{l} / \mathrm{hr}$ (versus $150 \mathrm{\ell} / \mathrm{hr}$ performance specification), the new liquefier spproximately doubles the output of the old unit.

To date the liquefier has logged over $5500 \mathrm{hr}$ of operating time in the nine months since its installation with no major failures and has exceeded all of its performance specifications. System operation is stable and surplus capacity exists while supporting all connected users. Uninterrupted operation for long periods has been possible with the new liquefier. A large silica-gel adsorber
Table III

DIII-D Cryoaystem Parameter

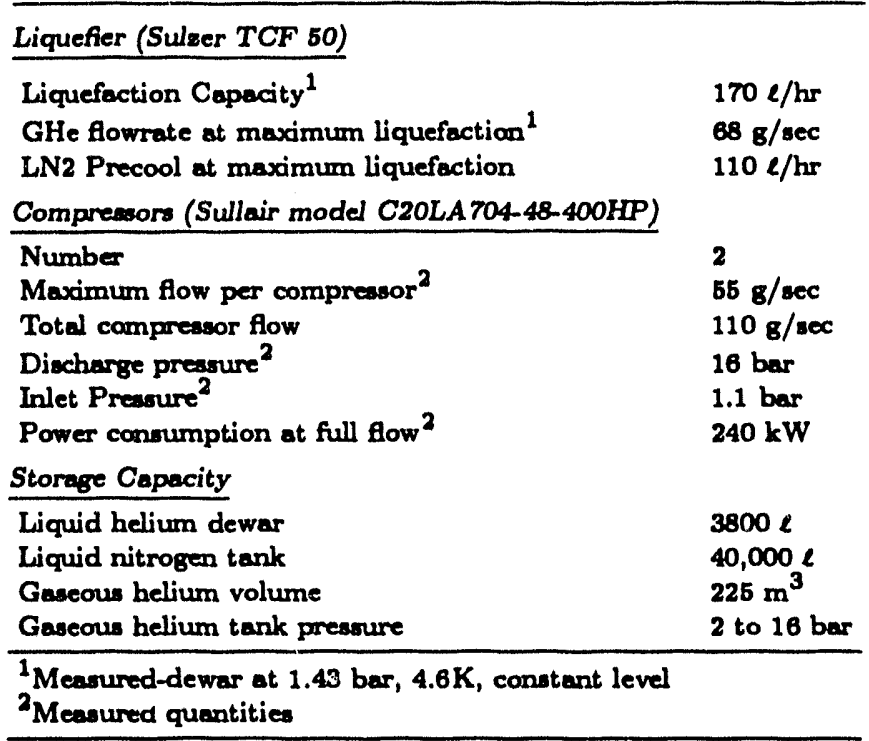

at $80 \mathrm{~K}$ and a smaller adsorber at $20 \mathrm{~K}$ have been useful in removing contamination from the helium stream. The new liquefier has operated for up to 12 weeks continuously without regeneration of the adsorbers with no decrease in performance. The old liquefier had a pair of small switchable adsorbers at $80 \mathrm{~K}$ and no $20 \mathrm{~K}$ adsorber. Historically it had to be shut down after three to four weeks of continuous operation due to diminished performance caused by impurity buildup in the liquefier.

\section{B. Compressors}

Compressed gaseous helium is provided by an identical pair of Sullair oil-flooded screw compressors. The compressors are single stage and may be operated independently. Each compressor produces a measured flow of $55 \mathrm{~g} / \mathrm{sec}$ at a discharge pressure of 16 bar and a suction line pressure of 1.1 bar. The compressors are equipped with remotely controllable slide valves to reduce the compressor flow and power consumption as system gas re quirements change. A dedicated water cooling tower provides cooling to both of the compressors.

Oil removal from the helium stream is critical since the screw compressors are oil flooded for sealing and cooling purposes. Oil removal is accomplished in three steps. First, oil is removed in the bulk separator module supplied by Sullair to approximately $200 \mathrm{ppm}$. Second, the helium stream passes through 3 stages of progressively finer coalescing filters where the oil contamination is further reduced to $1 \mathrm{ppm}$. Finally, the helium stream passes through a large activated carbon bed where the residual oil level is reduced to less than less than $20 \mathrm{ppb}$. The high pressure helium stream is continuously monitored for oil, nitrogen and water using a Sulzer model WF34D-3 multicomponent detector combined with a model SM34 pyrolyzer. Maintenance of two large Sullair 
compressors is substantially less than that required for the smaller compressors which they replaced.

\section{Gas Management System}

The gas management system maintains constant pressure in the compressor discharge and suction piping while acting as a gas inventory control system. The helium gas storage pressure can vary between 2 and 16 bar, depending on the quantity of LHe which has been vaporized. The storage capacity was recently increased $50 \%$ by adding a $75 \mathrm{~m}^{3}$ tank to accommodate the maximum cryosystem liquid inventory during shutdown periods when it is fully raporized. An upgrade of the gas management control system was required to prevent damage to the liquefier turbines due to rapid system pressure changes. The control system upgrades are discussed in [4].

\section{Distribution Bax}

The distribution box enables the selection of cryogen flow to any combination of the users. It contains the piping, automatic valves, and transferline terminations which connect the LHe dewar and the LN2 storage tank to the users. It also contains the return piping and valves to operate the neutral beam and advanced divertor cryopump reliquefiers. The distribution box was recently redesigried and rebuilt at General Atomics (GA) to accommodate the advanced divertor cryopump system and the pellet injector. The design is relatively compact due to limited space. The existing manual valves were replaced with 20 pneumatically actuated cryovalves allowing fully automatic operation. Automation has allowed a variety of operational tasks to be performed by PLC control in addition to improving safety by providing a means of automatic shutdown of cryogen supply in case of emergency.

\section{E. Neutral Beam Wet Expander}

The original neutral beam reliquefier contained a heat exchanger, Joule-Thomson valve, the bayonet connections and various instrumentation. It was designed by Cryogenic Consultants Inc. of Allentown, PA and supported the operation of three beamlines. A fourth neutral beamline was added in 1986 as part of the DIII-D upgrade. This placed an additional heat load on the cryosystem and the net production rate with four beamlines was close to zero. This made operations complicated often forcing the shutdown of one or two beamlines over the weekend to re-establish liquid inventory.

A more efficient liquefaction process can be achieved using a so-called "wet-expander" in which the cold high pressure gas flowing in the secondary side of the heat exchanger performs mechanical work as it expands against a piston device [6]. The design and construction of a wet expander was undertaken soon after the fourth beamline was commissioned. The rotating machinery was supplied by Koch and modified and packaged by
GA. The wet expander is now used in place of the Joule-Thomson valve resulting in substantially increased overall efficiency. An overall net liquefaction rate of 20 to $30 \mathrm{l} / \mathrm{hr}$ was achieved while supporting four beamlines using the wet expander with the old liquefier.

\section{F. Control System}

Control and operation of the cryosystem has been largely automated using a PLC besed control system. The goal of control system upgrades has been to improve reliability and facilitate one-shift operation. The operator initiates modes and monitors the system from a graphical display terminal located in the cryogenic control room. Engineers use IBM PC compatible terminals at home to emulate the graphical display by logging onto the system via a modem connection. An sutomatic dialing telephone system is used to call personnel at home or by pocket pager when system trouble arises during off hours.

\section{CONCLUSION}

An overview of the upgraded DIII-D cryosystem has been presented. The system has been upgraded as demands for liquid helium have increased. New hardware has been selected and installed to increase production while satisfying the goals of increased automation, greater reliability and reduced maintenance. Major upgrades to the control system have allowed one-shift operation of the system and reduced the number of off-hours personnel call-ins. The present system has the capability to support all installed users as well as those planned for future installation.

\section{ACKNOWLEDGMENTS}

The authors wish to express their gratitude to D. Cummings, J. Harris, L. Jensen, H. Lizarraga, E. Taylor, and R.S. Williams. These technicians have devoted long hours to construct the system and responded at all hours of the day and night to keep the cryosystem operational.

\section{REFERENCES}

[1] A.R. Langhorn, "The Doublet III neutral beam injector cryosystem," in Advances in Cryogrenic Engineering, vol. 29. New York, NY: Plenum, 1883.

[2] J. Kim, R.W. Callis, A.P. Colleraine, J. Cummings, A.S. Gled, A.M. Gootgeld, et al., "Performance of the DIII-D neutral beam injection syatem," in Proc. 12th Symp. on Fusion Engineering, Monterey, 1887.

[3] K.M. Schaubel, C.B. Baxi, G.L. Campbell, G.J. Laughon, M.A. Mahdavi, M.M. Menon, et al., "The development of an in-veasel cryopump syatem for the DIII-D tolamak," in Advances in Cryogenic Engineering, val "39. New York, NY: Plemum, 1993.

[4] G.L. Campbell, J.J. Gilgallon, and K.M. Schmubel, "DIII-D cryogenice control system statu," this symposium.

[5] G.L. Campbell and J.J. Harris, "DIII-D cryogenic syatem control system upgrade," in Proc. 13th Symp. an Fusion Engineer ing, Knoxville, 1889.

[6] K.D. Williammon, Jr. and F.J. Edeakuty, in Liquid Cryogrenic Volume I: Theory and Equipment, Boca Raton, FL: CRC Preas, 1833, pp. 72-78. 
